CORRESPONDENCE

Semenza G, Auricchio S. Small-intestinal disaccharidases. In: Scriver C, Beaudet A, Sly W, ease. 6th ed. New York: McGraw-Hill, 1989; vol 2: 2975-97.

\section{In defence of goniotomy}

High prevalence of lactose absorbers in patients with presenile cataract from northern Sardinia

EDITOR,-An elevated incidence of cataract has been observed by Simoons et al in high milk drinking populations. ${ }^{1}$ Other authors ${ }^{2} 4$ found that the percentage of lactose absorbers among subjects with cataract was higher than in the normal population. We studied 40 adult male subjects with cataract (they were aged less than 56 years and more than 44 years), and 50 healthy similarly aged control males from northern Sardinia. Milk drinking habits were similar for the two groups. None of the patients was affected by cataract dueto congenital, inflammatory, iatrogenic, diabetic, traumatic factors, or other causes. Thirty five of the 40 cataractous subjects had bilateral cataract, 23 of whom had nuclear, seven cortical posterior, six coronary, two posterior polar, and two zonular cataract. All the subjects were given a $50 \mathrm{~g}$ oral load of lactose as a $15 \%$ water solution; the hydrogen breath concentration in the expired air was measured in each subject before the lactose oral load and at 30 minute intervals for the next 4 hours using a Quintron 121 gas chromatograph. Lactose malabsorption was diagnosed if the maximum increase in hydrogen in the expired air was more than 20 parts per million. ${ }^{5}$ Only seven $(14 \%)$ of the 50 normal subjects were lactose absorbers compared with $16(40 \%)$ of the 40 cataractous subjects. The $\chi^{2}$ test revealed a significant difference $(p=0.01)$ in the frequencies of the two groups. One fact that must be emphasised is that all the lactose absorber cataractous patients had bilateral nuclear cataract; the difference between the frequency of this subgroup and the control group is highly statistically significant. These results confirm that in our region (northern Sardinia), characterised by high milk drinking habits, adult lactose absorbers are more prone to develop presenile cataract than non-lactose absorbing individuals.

GIANFRANCO MELONI AUGUSTO OGANA MARIA CHIARA MANNAZZU TULLIO MELONI Clinica Pediatrica FRANCO CARTA ADOLFO CARTA Clinica Oculistica, Università di Sassari Viale San Pietro 12, 07100 Sassari, Italy

1 Simoons FJ. A geographic approach to senile cataracts: possible links with milk consumption, lactase activity and galactose metabolism. Dig Dis Sci 1982; 27: 257-64.

2 Rinaldi E, Albini L, Costagliola C, De Rosa G, Auricchio G, De Visia B, et al. High frequency Auricchio G, De Visia B, et al. High frequency
of lactose absorbers among adults with idioof lactose absorbers among adults with idiotion with a high prevalence of primary adult tion with a high prevalence of primary adult
lactose malabsorption. Lancet $1984 ; \mathrm{i}: 355-7$.

lactose malabsorption. Lancet 1984; i: 355-7.
Spinelli D, Vota MG, Formenti F, Accetta S, Careddu P, Roggero P, et al. Idiopathic pre-
Cinelli D, Vota MG, Formenti F, Accetta S, senile and senile cataract formation and changes in lactase activity. Fortschr Ophthalmol 1987; 84: 666-8.

4 Birlouez-Aragon I, Stevenin L, Rouzier C, Brivet $M$. Consommation de lactose et activit lactasique: deux facteurs de risque de la cataracte sénile et diabetique. Age/Nutrition 1990; 1: 74-9. 'primary trabeculectomy has replaced goniotomy as the preferred surgical treatment for congenital glaucoma'. ${ }^{1}$ To support this statement he cites Burke and Bowell's report of an $87 \%$ success rate for primary trabeculectomy based on 13 eyes with primary infantile glaucoma and a mean follow up of 3.9 years. ${ }^{2}$ Rice has reported an $86 \%$ success rate $(211 / 246$ eyes) for goniotomy for eyes with primary infantile glaucoma which in the majority $(73 \%)$ of cases only required a single procedure. ${ }^{3}$ We reported a large long term follow up study of Rice and Lister's patients with trabeculodysgenesis (339 eyes) in which we showed that $92 \%$ of eyes controlled in infancy by goniotomy were still controlled after 5 years of follow up; however, KaplanMeier actuarial survival curves demonstrate that there is a risk of relapse throughout life. ${ }^{4}$ The risk of relapse in eyes having undergone trabeculectomy in childhood is significant especially if antiproliferative agents are not used. ${ }^{5}$ The advantage of a primary goniotomy is that the conjunctiva is preserved for any future drainage surgery. For individual children, if they are to have a drainage operation, it will be when they are older and young age is a significant negative factor in bleb survival. Also there will hopefully have been advances in both surgical techniques and in agents used to improve bleb survival.

O'Connor also cites Miller and Rice ${ }^{5}$ as advocating primary trabeculectomy. This appears to be a misquote as their paper reports trabeculectomy being performed in eyes with relapse or failure of control of congenital glaucoma after goniotomy or trabeculotomy.

My remarks refer entirely to eyes with beculodysgenesis using the Hoskins classificongenital glaucoma seen in the UK and to the results for a surgeon experienced in the technique of goniotomy. Examination of the angle is crucial when planning the surgical approach. Goniotomy should never be performed without a view of the angle. However, a view of the angle can be usually achieved by removal of the corneal epithelium. O'Connor states that goniotomy cannot be performed in approximately $50 \%$ of cases of congenital glaucoma because of corneal opacity. However, we found that in addition to the 211 patients reported in our study to have been treated by primary goniotomy, only a further 20 patients $(<10 \%)$ with trabeculodysgenesis were seen during the same time but were excluded from our paper as the initial surgery was not goniotomy. In most of these cases a primary trabeculotomy was performed as an adequate view of the angle could not be achieved because of corneal clouding. Trabeculotomy can be performed at a temporal, or even inferior, site to preserve the superior bulbar conjunctiva. The congenital glaucoma which occurs in Middle Eastern countries is more often familial than it is in the West ${ }^{7}$ and may respond less well to goniotomy. Often there is a more extensive angle anomaly (personal observation). I note that Elder's paper in the same issue of the $B \mathcal{} O$ relates to his experience in Jerusalem. ${ }^{8}$ It
EDITOR,-O'Connor's editorial states that typical primary congenital glaucoma (tracation ${ }^{6}$ ), which is the commonest form of may be that in this population and in eyes with iridotrabeculodysgenesis with infantile onset glaucoma, combined trabeculectomytrabeculotomy may be a useful operation. I, therefore, read his paper with interest and look forward to him reporting a longer follow up.

ISABELLE RUSSELL-EGGTTT Great Ormond Street Hospital,
London WC1N 3fH

1 O'Connor G. Combined trabeculotomytrabeculectomy for congenital glaucoma. $\mathrm{Br} \mathfrak{F}$ Ophthalmol 1995; 78: 735.

2 Burke JP, Bowell R. Primary trabeculectomy in congenital glaucoma. Brf Ophthalmol 1989; 73: 186-90.

3 Rice NSC. The surgical management of congenital glaucomas. Aust $\mathcal{F}$ Ophthalmol 1977; 5: 174-9.

4 Russell-Eggitt IM, Rice NSC, Barrie J, Wyse RKH. The relapse rate following surgery for trabecular dysgenesis. Eye 1992; 6: 197-200.

5 Miller MH, Rice NSC. Trabeculectomy combined with $\beta$ radiation for congenital glaucoma. Br $\mathcal{F}$ Ophthalmol 1991; 75: 584-90.

6 Hoskins HD Jr, Shaffer RN, Hetherington J. Anatomical classification of the developmental Anatomical classification of the developmental
glaucomas. Arch Ophthalmol 1984; 102: glaucomas.

7 Jaafar MS. Care of the infantile glaucoma patient. Ophthalmology annual. New York: Raven Press, 1988; 7: 15-37.

8 Elder MJ. Combined trabeculotomy-trabeculectomy compared with primary trabeculectomy for congenital glaucoma. Br $\mathcal{f}$ Ophthalmol 1994; 78: $745-8$.

\section{Adjustable sutures in eyelid surgery}

EDITOR,-I would like to comment on the article by J R O Collin and E A O'Donnell. ${ }^{1}$ In that article, they state that their technique of postoperative adjustment of lid height is new. Work I have done shows that the adjustable suture technique was introduced in 1982 and has been used with modifications for 12 years. $^{2}$

ROBERT G SMALL Dean $A M c$ Gee Eye Institute, 608 Stanton L Young Drive, Oklahoma City,
OK 73104, USA

1 Collin JRO, O'Donnell BA. Adjustable sutures in eyelid surgery for ptosis and lid retraction. $\mathrm{Br} \mathcal{F}$ Ophthalmol 1994; 78: 167-74.

2 Small RG. Upper eyelid retraction in Graves' ophthalmopathy: a new surgical technique and a study of the abnormal levator muscle. Tran Am Ophthalmol Soc 1988; 86: 725-93.

Reply

EDITOR,-In 1982, Small used a posterior approach technique to excise Muller's muscle and recess the aponeurosis with two monofilament polypropylene mattress sutures passed through the skin for later adjustment. In 1988 he modified the technique to an anterior approach, cut the levator muscle above Whitnall's ligament and held it recessed with a 6/0 monofilament polypropylene mattress suture brought through the skin. The suture is adjusted if necessary immediately after recovery from anaesthesia but by bringing the suture through a rubber cylinder cut from the edge of a surgical glove, the adjustment can be modified during the first postoperative week before finally tying the suture.

His paper shows some very impressive results and our recent paper confirms that adjustable sutures are very effective in treating lid retraction. We recess Muller's muscle with the aponeurosis and the levator muscle via an anterior approach and maintain the 
skin crease by passing the adjustable sutures into the tarsus at the level of the intended skin crease. This is a different technique from that described by Small, and allows the upper lid retractor complex not only to be recessed for the treatment of lid retraction but also to be resected and advanced for the correction of ptosis. We prefer our new technique, but should have given Small credit for his very real and original contribution to the use of adjustable sutures in lid retraction.

J R O COLLIN Moorfields Eye Hospital,

London EC1V 2PD

Effects of morphine on corneal sensitivity and epithelial wound healing

EDITOR,-Recently Peyman et al reported a fascinating study, demonstrating an analgesic effect of topically applied morphine formulation in patients with post-surgical corneal abrasions. ${ }^{1}$ Their results are in accordance with numerous clinical experiences within the past 10 years in different fields of acute and chronic pain therapy showing that a local application of opiates is useful in clinical practice. It might be of interest to Peyman and colleagues that the use of opiates as topical ophthalmic analgesics has been reported previously.

Remarkably, as seen from a communication of Keil, ${ }^{2}$ ophthalmic surgeons obviously used opiates in this way more than 500 years ago. In the late 14th century the most important old German ophthalmic monograph was published. The author (probably named 'meister Johannes'), of whom little is known, cited Arabic and Middle Ages authorities such as Arnald of Villanova. In this little book there are many prescriptions for 'krancke augen' (sick eyes), including some local - for example, corneal application of opium (poppy) for surgery and pain relief. Therefore, the indisputable merit of Peyman et al's paper is the rediscovery and scientific proving of an old medical technique.

CHRISTOPH MAIER

Clinic for Anästhesiology and Operative Intensive Care, University of Kiel Pain Clinic D24105 Kiel, Germany

1 Peyman GA, Rahimy MH, Fernandes ML Effects of morphine on corneal sensivity and epithelial wound healing: implications for topical ophthalmic analgesia. Brf Ophthalmol 1994 78: $138-41$.

2 Keil G. Pommersfeldener (schlesisches) Augenbüchlein. In: Ruh K, Keril G, Schröder W, Wachinger B, Worstbrock, eds. Die deutsch Literatur des Mittelalters. Verfasserlexikon. Vol 7. Berlin: Dr Gruyter, 1989, 778-9.

\section{Reply}

EDITOR,-We are flattered by Christoph Maier's letter regarding our paper. As they say, nothing is new under the sun! However, not having access to the German book that Maier cites, it is difficult to formulate an educated response. I believe, nevertheless, that the old literature has not alluded to the difference in analgesic effect of morphine between denuded and normal cornea and will not have comments regarding normal epithelial wound healing after application of this analgesic agent.
GHOLAM A PEYMAN

LSU Eye Center, 2020 Gravier Street, Suite $B$, New Orleans, $L A$ 70112-2234, USA

\section{Selective cell death in glaucoma}

EDITOR,-In his recent article J E Morgan raises various interesting theoretical points ${ }^{1}$ However, I would like to draw attention to several facts that I believe were not completely addressed in this article. We had previously analysed the lateral geniculate nucleus from patients with glaucoma, as well as a control population. ${ }^{2}$ We identified a selective diminution of cell density in the magnocellular system of glaucomatous patients. In describing our data on lateral geniculate changes in human glaucoma, Morgan suggests, first, that our technique incorrectly assayed cells per unit area rather than accurately considering volume. This methodological comment points up the tremendous difficulty in properly designing a valid stereological study, particularly when one examines cell bodies. However, we were able to avoid this pitfall. Rather than counting the cell body per se, we only included cells in which the nucleolus could be detected. This allowed for an accurate assessment of density, given that microscopic thickness could easily be determined. The conservation of nucleolar size between magnocellular and parvocellular cells, as well as the relatively small size of the nucleolus compared with the overall thickness of the sections, minimises the technical errors he suggests. Since the microscopic section has a fixed thickness, our measurements are indeed per unit volume, and not per unit area. More importantly, Morgan suggests that we have not adequately considered the possibility that lateral geniculate cell density might actually go up in the face of ganglion cell loss. We should point out that the seminal point of our paper was that we saw a differential effect on magnocellular and parvocellular tissue. No matter how you slice it (pun intended) this difference suggests that glaucoma is doing different things to the magnocellular and parvocellular systems. The simplest conclusion (supported by the majority of papers cited by Morgan) would be that even if glaucoma causes some parvocellular loss (as is most certainly the case), earlier damage is done at the magnocellular level.

This brings me to a more significant comment. It is certainly possible we are wrong, and that some as yet undetermined flaw in our study (or those of other groups) has confounded the issue. But Morgan does not cite any refereed work supporting the hypothesis that glaucoma does not firs damage large retinal ganglion cells, while there are many publications supporting this hypothesis. We certainly recognise that these data contradict the fondly held hypothesis that glaucomatous damage is not preferentia to the magnocellular system. I would be the last to suggest that our data are unquestionably definitive, and that we know that glaucoma beyond all doubt damages larger cells and therefore the magnocellular system first. But the weight of published data does support this statement, and until new data are presented, the current answer to Morgan's question-does selective cell damage in glaucoma occur - must be yes.

Nevertheless, we would like to reinforce one corollary of our work that was alluded to obliquely in our article. The anatomical and functional elegance of the magnocellular and parvocellular layering of the lateral geniculate nucleus has led to the seductive but unfortunately incorrect assumption that a similar simple distinction of magnocellular and parvocellular cells exist at the level of the retina. The retinal ganglion cell layer contains a plethora of cell types, and we have as yet only a limited knowledge of how these cell types function in the normal as well as the glaucomatous retina. Future psychophysical and histopathological studies will hopefully shed light on what is a most compelling question.

EVAN B DREYER , al School, Massachusetts Eye and Ear Infirmary, Department of Ophthalmology, Glaucoma Consultation Service, 243 Charles Street Bostom MA02114-3096, USA

1 Morgan JE. Selective cell death in glaucoma: does it really occur? $\mathrm{Br} \mathcal{f}$ Ophthalmol 1994; 78: 875-80.

2 Chaturvedi N, Hedley-White ET, Dreyer EB. Lateral geniculate nucleus in glaucoma. $A m \mathcal{F}$ Ophthalmol 1993; 116: 182-8.

\section{Reply}

EDITOR,-Dreyer discusses some important aspects of his work on the lateral geniculate nucleus in glaucoma. ${ }^{1}$ In my review I referred specifically to the volume of the geniculate laminae and not to the calculation of cell density. The finding of a differential effect on the density of geniculate cells in magnocellular and parvocellular laminae is interesting and is not what is at issue here. The point is that without reference to the lamina volume, density measurements per se do not indicate changes in the number of cells in a given population.

A decrease in cell density certainly reflects cell loss (assuming that expansion of the geniculate laminae had not occurred) However, changes in cell density are the product of changes in the total cell population and laminar volume. In macaques, for example, the cell density is deafferented laminae can increase by as much as $53 \%$ but when the lamina volume is taken into account the estimated decrease in the cell population for that lamina is of the order of $22 \% .^{2}$ In the human, monocular enucleation results in marked geniculate cell loss ${ }^{3}$ but the change in cell density in the deafferented laminae is minimal because of laminar shrinkage. A similar process may explain why the parvocellular cell densities in Dreyer's study did not change significantly even with the inclusion of subjects with extensive glaucomatous damage. The differential effects of glaucoma on cell densities could reflect selectively greater cell death in the magnocellular laminae. However, caution must be exercised in drawing this conclusion without knowing the degree of laminar shrinkage.

The aim of the review was to emphasis alternative explanations of the published data on selective cell death in glaucoma and not to decide in favour of selective or non-selective mechanisms. I referred to one importan paper that certainly raises questions about the role of selective cell death. Casson et al found that defects occurred in both temporal modulation and blue yellow sensitivity at a similar stage in the disease, arguing agains selective $\mathbf{M}$ or $\mathbf{P}$ pathway damage. Further work needs to be done to characterise the anatomical changes that occur early in 